\title{
Çukurova Koşullarında II. Üründe Yetiştirilecek Yağlık Ayçiçeğinde (Helianthus annuus L.) En Uygun Ekim Zamanının Belirlenmesi Üzerine Bir Araştırma
}

\author{
*Abdullah Çíl Ayşe Nuran Çíl Vakas ŞAHIN M. Reis AKKAYA \\ Doğu Akdeniz Tarımsal Araştırma Enstitüsü Müdürlüğü, Adana \\ *Sorumlu yazar e-posta (Corresponding author e-mail): abdullah.cil@tarim.gov.tr
}

\section{Öz}

Ayçiçeğinde (Helianthus annuus L.), özellikle kurak ve yarı kurak alanlar için önemli bir yağ bitkisidir. Bu araştırma, iki ayçiçeği çeşidinde farklı ekim zamanlarının verim ve kalite üzerine etkilerini incelemek amacıyla, 2010-2011yıllarında Adana II. Ürün sulu koşullarında yürütülmüştür. Tesadüf Bloklarında Bölünmüş Parseller deneme metoduna göre kurulan denemede, ekim zamanları (12 Haziran, 22 Haziran, 02 Temmuz, 12 Temmuz ve 22 Temmuz) ana parsellerde, ayçiçeği çeşitleri (Şems ve Sanbro) alt parsellerde yer almıştır. Araştırmada, erkencilik, bitki boyu, tane verimi, 1000 tane ağılığı, tabla çapı, yağ oranı ve yağ verimi değerleri incelenmiştir. Denemede ekim zamanına göre; tane verimi $169.7-349.7 \mathrm{~kg} / \mathrm{da}$ bitki boyu $139.5-170.5 \mathrm{~cm}$, 1000 tane ağırlığı 43.3-58.9 g, tabla çapı 15.5-22.9 cm, yağ oranı 29.96-40.37 ve erkencilik 48.1-54.7 gün arasında değiştiği tespit edilmiştir. Çukurova Bölgesinde II. Ürün koşullarında yetiştirilecek yağlık ayçiçeği için en uygun ekim zamanı 12 Haziran olarak belirlenmiştir. Ancak ekim zamanı erkene çekildikçe verimin arttığı belirlenmiştir.

Anahtar Kelimeler: Helianthus annuus L., yağ verimi, yağ oranı, ekim zamanı

\section{A Study on Determination of the Best Sowing Date for Sunflower (Helianthus annuus L.) as Second Crop in Çukurova Conditions}

\begin{abstract}
Sunflower (Helianthus annuus L.), is an important oil plant especially for arid and semiarid regions. The present study was carried out to determine the effect of different sowing dates on seed yield and quality in two sunflower cultivars grown in second crop watery conditions of Adana in 2010-2011. The field experiment was set up in a split plot design and two sunflower varieties (Şems and Sanbro) were assigned to the main plots and and five sowing dates (12 June, 22 June, 02 July, 12 July and 22 July) were assigned to the subplots. In the study, earliness, plant height, grain yield, 1000-grain weight, head diameter, oil ratio and oil yield values were examined. According to the trial sowing dates; Grain yield $169.7-349.7 \mathrm{~kg} / \mathrm{da}$ plant height $139.5-170.5 \mathrm{~cm}, 1000$-grain weight $43.3-58.9 \mathrm{~g}$, head diameter $15.5-22.9 \mathrm{~cm}$, oil ratio $29.96-40.37 \%$, oil yield $52.36-141.3 \mathrm{~kg} / \mathrm{da}$ and earliness 48.1-54.7 days has been found. Çukurova region at the most appropriate time for sowing oilseed sunflower to be grown in the second crop has been identified as June $12^{\text {th }}$. However, when sowing date was witdrawn early, determined to increase the efficiency of yield.
\end{abstract}

Keywords: Helianthus annuus L., sunflower, seed yield, oil ratio, sowing date

\section{Giriş}

A yçiçeği hemen her bölgemizde A yetiştirilebilen ve tanelerinde yüksek oranda kaliteli yağ bulunduran, ekim alanı, üretimi ve yağ üretimi bakımından ilk sırada yer alan önemli bir yağ bitkisidir. Bu nedenle ülkemiz ayçiçeği üretiminin arttırılması için uygun koşullara sahiptir. Günümüzde ayçiçeği ekim alanını artırmada, I. ve II. ürün tarımı olarak, GAP ve Akdeniz bölgeleri potansiyel görülmektedir
(Kolsarıcı ve ark. 2006). Bölgemizde 2004 yılında 75.980 dekar olan ayçiçeği ekim alanı 2014 yılına gelindiğinde 442.341 dekarı aşarak ülkemizin ihtiyaç duyduğu bitkisel yemeklik yağ üretiminde aldığı payı da artmıştır (Anonim 2015). Bugün ülkemizde yağ elde edilen bitkiler içerisinde, insan beslenmesinde tüketilen sıvı yağların \%74'ü ayçiçeğinden elde edilmektedir (Taşkaya ve Uçum 2012). Öte yandan, nüfus 
artış hızına göre bitkisel yağ üretimimizin yetersiz olduğu göz önüne alındığında, ayçiçeği üretiminin arttırılması kaçınılmazdır. Üretim artışı ekim alanı veya birim alan verimi artışıyla gerçekleştirilebilir. Bilindiği üzere verim, genotip ve çevrenin ortak etkileşiminin bir sonucu olup, çevre koşullarını ise iklim, toprak yapısı ve yetiştirme teknikleri (ekim nöbeti, ekim zamanı, sulama vb) gibi faktörler oluşturmaktadır. Yetiştirme teknikleri içerisinde yer alan ekim zamanının verim üzerine etkisi çok fazla olup, erken ekim \%25-35 verim artışı sağlamaktadır.

Çukurova bölgesi gibi sulama olanaklarının olduğu bir bölgede bitkisel üretimi arttırmanın yollarından biri de, ekolojik şartlara bağıı olarak yılda birden fazla ürün almaktır (Tansı 1987). Ayçiçeği tarımında üretim için $21-24^{\circ} \mathrm{C}$ gündüz hava sıcaklığı optimumdur. $36-40^{\circ} \mathrm{C}$ 'nin üzerindeki yüksek sıcaklıklarda polen tozu çimlenemediği için, yabancı tozlanma tehlikeye düşmektedir. Çukurova bölgesinde, ilkbahar ekimlerinde, hava sıcaklığı bitkinin büyüme ve gelişmesi üzerine olumsuz etki yapmamakta. Ancak; ikinci ürün ekimlerinde özellikle çiçeklenme döneminde ortaya çıkan yüksek sıcaklık, döllenmeyi olumsuz etkilemektedir. Yetişme süresindeki, özellikle tohumun gelişme döneminde, ortaya çıkan yüksek sıcaklık, yağ asitleri bileşimini etkileyebilmektedir ve yağın kalitesini düşürmektedir. Yetişme süresi boyunca ortaya çıkan yüksek sıcaklık, protein oranını yükseltmekte, yağ oranını ise azaltmaktadır. Ekim zamanını belirleyen önemli unsurlardan birisi de yetiştirildiği bölgenin iklim koşullarıdır. Sulu tarımın yapıldığı yerlerde ekim işleminin Mayıs-Haziran arasında yapılabileceği ifade edilmektedir (Kolsarıcı ve ark. 1987). Çukurova Bölgesinde yazlık olarak kuru koşullarda tarımı yapılan Ayçiçeği, ülkemizde birçok bölgede olduğu gibi ekim nöbeti sistemlerinde I. Ürün ile birlikte II. ürün olaraktan kolaylıkla yer alabilir. Yaptığımız çalışmada bölgemizde ayçiçeğinin ikinci ürün tarımında en uygun ekim zamanının belirlenmesine çalışılmıştır.

\section{Materyal ve Yöntem}

$\mathrm{Bu}$ araştırma, iki ayçiçeği çeşidinde farklı ekim zamanlarının verim ve kalite üzerine etkilerini incelemek amacıyla, 20102011yıllarında Adana II. Ürün sulu koşullarında yürütülmüştür. Tesadüf Bloklarında Bölünmüş Parseller deneme metoduna göre kurulan denemede, ekim zamanları (12 Haziran, 22 Haziran, 02 Temmuz, 12 Temmuz ve 22 Temmuz) ana parsellerde, ayçiçeği çeşitleri (Şems ve Sanbro) alt parsellerde yer almıştır. Denemeler 3 tekerrürlü olacak şekilde kurulmuş, parsel uzunluğu $6.0 \mathrm{~m}$, sıra arası mesafe $70 \mathrm{~cm}$. ve sıra üzeri mesafe sulu koşullarda $30 \mathrm{~cm}$ olmak üzere, ekilen parsel alanı $(0.7 \times 6.0 \mathrm{~m} \times 4$ sıra) $16.80 \mathrm{~m}^{2}$ olarak planlanmıştır. Araştırma denizden $12 \mathrm{~m}$ yükseklikte, $36^{\circ} 51^{\prime}$ Kuzey enlemi ile $35^{\circ} 20^{\prime}$ Doğu boylamları arasında yer alan Doğu Akdeniz Tarımsal Araştırma Enstitüsünün Doğankent lokasyonu taban koşullardaki deneme alanında 2010 ve 2011 yıllarında yürütülmüştür. Adana ilinin 2010 ve 2011 yılları ile uzun yıllar ortalama yağış ve nispi nem değerleri Çizelge 1' de verilmiştir. Deneme yıllarında ortalama sıcaklıklar, uzun yıllar (19752010) ortalama sıcaklıklarının altında seyretmiştir. 2010 yılı maksimum sıcaklık ortalamaları uzun yıllar maksimum sıcaklık ortalamalarının üzerinde gerçekleşmiştir. 2011 yılında ise uzun yıllar ortalama sıcaklıklarının altında seyretmiştir. Deneme yıllarındaki toplam yağış miktarları incelendiği zaman, her iki yılda da uzun yıllar ortalamasına göre daha kurak geçtiği anlaşılmaktadır. Nispi nem oranı denemenin yürütüldüğü her iki yılda da yıllara bağlı olarak farklılık göstermiştir (Çizelge 1).

Araştırma alanının toprakları Seyhan nehrinin taşkınlarıyla getirilip depolanan ince tekstürlü, yaşlı nehir terası toprakları olup, Arıklı serisindendir. Topoğrafyası düz ve düze yakın konumludur. AC horizonlu olan bu topraklar oldukça yüksek oranda kil ve kireç içeriğine sahiptir. Profillerinde az da olsa kireç hareketi görülmektedir. Katyon değişim kapasiteleri 2325 me/100g. arasında değişmekte olup, bu topraklarda smektit ve kaolinit grubu kil mineralleri baskın kil tipini oluşturmaktadır. Profildeki kil miktarı \%1.25 civarındadır (Dinç ve ark. 1995). Araştırma alanından alınan toprak numunelerinin Çukurova Üniversitesi Ziraat Fakültesi Toprak Bölümünde yapılan kimyasal analiz sonuçları Çizelge 2'de verilmiştir. Çizelge 2 incelendiğinde; bu toprakların organik madde bakımından zayıf, kireç yönünden zengin olduğu (Madran 1991), toprak PH'sının hafif alkali tepkimeli, tuzluluk yönünden çok düşük (Dinç ve ark. 1995) ve mikro elementler yönünden ( $Z n$, $\mathrm{Fe}, \mathrm{Cu}$, ve $\mathrm{Mn}$ ) ise bitki beslemesi açısından 
Çizelge 1. Adana ili 2010, 2011 ve uzun yıllar ortalama sıcaklık, ortalama sıcaklık $\left({ }^{\circ} \mathrm{C}\right)$, nispi nem $(\%)$ ve toplam yağış $(\mathrm{mm})$ ortalama aylık değerleri

Table 1. Average temperatures, total precipitations and moisture contents of Adana province in 2010, 2011 and long term

\begin{tabular}{cccccccccc}
\hline \multirow{2}{*}{ Aylar } & \multicolumn{3}{c}{ Ortalama Sıcaklık $\left({ }^{\circ} \mathrm{C}\right)$} & \multicolumn{3}{c}{ Nispi Nem $(\%)$} & \multicolumn{3}{c}{ Toplam Yağış $(\mathrm{mm})$} \\
\cline { 2 - 10 } & $\begin{array}{l}\text { U. } \\
\text { Yıllar }\end{array}$ & 2010 & 2011 & $\begin{array}{c}\text { U. } \\
\text { Yıllar }\end{array}$ & 2010 & 2011 & U. & 2010 & 2011 \\
\hline Haziran & 25.2 & 25.0 & 24.5 & 66.0 & 61.1 & 72.4 & 22.4 & 1.4 & 0.0 \\
Temmuz & 29.7 & 27.8 & 25.9 & 68.0 & 71.3 & 71.5 & 5.4 & 0.7 & 0.0 \\
Ağustos & 28.1 & 30.2 & 28.8 & 67.0 & 67.4 & 68.6 & 5.1 & 0.0 & 0.0 \\
Eylül & 25.4 & 27.2 & 26.9 & 63.0 & 66.9 & 65.8 & 14.8 & 1.7 & 0.0 \\
\hline Ortalama & 27.1 & 27.5 & 26.5 & 66.0 & 66.7 & 69.6 & - & - & - \\
\hline Toplam & & & & & & & 47.7 & 3.8 & 0.0 \\
\hline
\end{tabular}

Kaynak: Devlet Meteoroloji İşleri Bölge Müdürlüğü Kayıtları, Adana

Source: Turkish State Meteorological Service Records, Adana

Çizelge 2. Araştırma alanı topraklarının kimyasal analiz sonuçları

Table 2. Chemical analysis results of research area

\begin{tabular}{ccccccccc}
\hline $\begin{array}{c}\text { Toprak } \\
\text { Derinliği } \\
(\mathrm{cm})\end{array}$ & $\begin{array}{c}\text { Organik } \\
\text { Madde } \\
(\%)\end{array}$ & $\begin{array}{l}\text { Kireç } \\
(\%)\end{array}$ & $\mathrm{pH}$ & $\begin{array}{c}\text { Tuz } \\
(\%)\end{array}$ & $\begin{array}{c}\text { Zn } \\
(\mathrm{ppm})\end{array}$ & $\begin{array}{c}\text { Fe } \\
(\mathrm{ppm})\end{array}$ & $\begin{array}{c}\mathrm{Cu} \\
(\mathrm{ppm})\end{array}$ & $\begin{array}{c}\mathrm{Mn} \\
(\mathrm{ppm})\end{array}$ \\
\hline $0-20$ & 1.70 & 16.33 & 7.88 & 0.05 & 0.11 & 4.67 & 1.02 & 3.40 \\
$20-40$ & 1.33 & 17.56 & 7.94 & 0.07 & 0.12 & 4.37 & 1.00 & 3.16 \\
$40-60$ & 0.94 & 21.90 & 8.08 & 0.08 & 0.12 & 3.26 & 1.01 & 2.35 \\
\hline
\end{tabular}

* Çukurova Üniversitesi Ziraat Fakültesi Toprak Bölümü-Adana

* Çukurova University Faculty of Agriculture Department of Soil Science, Adana

yeterli düzeylerde bulunduğu anlaşılmaktadır. (Zabunoğlu ve Karaçal 1986).

Genelde derinlere inildikçe organik madde oranı ile mikro elementlerden $\mathrm{Fe}$ ve $\mathrm{Mn}$ miktarlarının azalma yönünde; kireç ve tuz yüzdeleri ile $p H$ 'nın artış yönünde bir seyir takip ettiği, $\mathrm{Zn}$ ve $\mathrm{Cu}$ miktarlarının aynı düzeylerde kaldığı, özellikle 40-60 cm'lik toprak derinliğinde kireç birikiminin olduğu gözlenmektedir. Araştırmadan elde edilen verilerin varyans analizleri JMP 7.0 (Copyright $^{\odot} 2007$ SAS Institute Inc.) paket programı kullanılarak yapılmış, önemli bulunan faktör ortalamaları LSD testi ile gruplandırılmıştır.

\section{Bulgular ve Tartışma}

Bu araştırmanın sonuçlarına göre, ikinci ürün ayçiçeği ekim zamanalarının incelenen özellikler arasında önemli farklııkların oluğunu ve incelenen tüm özelliklerin ortalama değerleri ile bu ortalamaların istatistikî açıdan arz ettiği önem Çizelge 3'te verilmiştir. Çiçeklenme gün sayısı bakımından ekim zamanları arasındaki farklııı istatistiksel olarak önemli bulunmuştur. Denemeye alınan ekim zamanlarında en erken çiçeklenme gün sayısı Temmuz-22 (48.1gün) ekim zamanında ölçülürken, en geç çiçeklenme gün sayısı ise Haziran-12 (54.7gün) ekim zamanında elde edilmiştir.
Çizelge 3 incelendiğinde, uygulanan ekim zamanlarında bitki boyu açısından birbirleri ile karşılaştırıldığında en uzun boya sahip ekim zamanı $191.7 \mathrm{~cm}$ ortalama ile Haziran-22 olmuştur. Bunu Haziran-12 ekim zamanı izlemiştir. En kısa ekim zamanı ise ise $153.5 \mathrm{~cm}$ ortalama ile Temmuz-22 ekim zamanı olmuştur. Araştırmada bitki boyu bakımından uygulanan ekim zamanları birbirleriyle mukayese edildiğinde farklı sonuçlar oluşturmuşlardır. Bitki boyu, iklim ve toprak koşullarından ileri gelen çevresel değişikliklerden etkilendiği bildirilmektedir (Kıllı 1995).

Tohum verimi ile yakından ilgili olan tabla çapı ekim zamanlarına göre farklılık göstermiş ve 15.5 ile $22.9 \mathrm{~cm}$ arasında değişen değerler elde edilmiştir. En yüksek tabla çapı Haziran-12 ekiminde elde edilirken en küçük tabla çapı ise Temmuz-22 ekiminden elde edilmiştir (Çizelge 4). Ayçiçeğinde tabla çapı; ekolojik koşullara, toprak yapısına, yetiştirme tekniklerine, sulama durumuna ve çeşit faktörlerine bağlı olarak çok farklılık gösterdiği Gürbüz ve ark. (2003) tarafından ifade edilmiştir.

Bin tane ağırlığı açısından ekim zamanları birbirleri ile karşılaşı̧ııldığında istatitiki açıdan fark önemli olmuştur. En yüksek bin tane ağırlığı Haziran-12 ekiminden (58.9 gr) elde edilmiş, en 
Çil ve ark. "Çukurova Koşullarında II. Üründe Yetiştirilecek Yağlık Ayçiçeğinde (Helianthus annuus L.) En Uygun Ekim Zamanının Belirlenmesi Üzerine Bir Araştırma"

Çizelge 3. Denemeye alınan ayçiçeği çeşitlerinin incelenen özelliklere ait ortalama değerler* Table 3. Averages of some traits of sunflower varieties

\begin{tabular}{|c|c|c|c|c|c|c|c|c|c|c|c|c|}
\hline \multirow{3}{*}{$\begin{array}{c}\begin{array}{c}\text { Zaman } \\
\text { Uygulaması }\end{array} \\
\text { Haziran-12 }\end{array}$} & \multicolumn{6}{|c|}{ \% 50 Çiçeklenme Gün Sayısı(gün) } & \multicolumn{6}{|c|}{ Bitki Boyu $(\mathrm{cm})$} \\
\hline & \multicolumn{2}{|c|}{2010} & \multicolumn{2}{|c|}{2011} & \multicolumn{2}{|c|}{ Ortalama } & \multicolumn{2}{|c|}{2010} & \multicolumn{2}{|c|}{2011} & \multicolumn{2}{|c|}{ Ortalama } \\
\hline & 53 & a & 56.3 & a & 54.7 & a & 155.4 & a & 177.6 & $\mathrm{~b}$ & 166.5 & $b^{a}$ \\
\hline Haziran-22 & 50 & $\mathrm{~b}$ & 55.3 & $a b$ & 52.7 & $\mathrm{~b}$ & 149.3 & $a b$ & 191.7 & a & 170.5 & a \\
\hline Haziran-02 & 49 & c & 54.7 & $b$ & 51.8 & c & 140.1 & bc & 177.4 & $b$ & 158.7 & $b$ \\
\hline Haziran-12 & 49 & c & 53.3 & c & 51.2 & c & 133.3 & $\mathrm{~cd}$ & 166.5 & c & 149.9 & c \\
\hline Haziran-22 & 45 & $d$ & 51.4 & $d$ & 48.1 & $d$ & 125.1 & $d$ & 153.5 & $d$ & 139.5 & d \\
\hline Ortalama & \multicolumn{2}{|c|}{49.2} & \multicolumn{2}{|c|}{54.2} & \multicolumn{2}{|c|}{51.7} & \multicolumn{2}{|c|}{140.6} & \multicolumn{2}{|c|}{173.3} & \multicolumn{2}{|c|}{157} \\
\hline C.V.(\%) & \multicolumn{2}{|c|}{8.6} & \multicolumn{2}{|c|}{1.71} & \multicolumn{2}{|c|}{1.94} & \multicolumn{2}{|c|}{8.46} & \multicolumn{2}{|c|}{5.03} & \multicolumn{2}{|c|}{6.59} \\
\hline $\operatorname{LSD}(0.05)$ & \multicolumn{2}{|c|}{0.5} & \multicolumn{2}{|c|}{1.13} & \multicolumn{2}{|c|}{0.83} & \multicolumn{2}{|c|}{14.57} & \multicolumn{2}{|c|}{10.68} & \multicolumn{2}{|c|}{8.57} \\
\hline
\end{tabular}

*: Her bir sütundaki aynı harfi taşıyan ortalamalar arasındaki fark önemsizdir $(P<0.05)$

*. Differences between averages with same letter in a column are statistically not important $(P<0.05)$

Çizelge 4. Denemeye alınan ayçiçeği çeşitlerinin incelenen özelliklere ait ortalama değerler* Table 4. Averages of some traits of sunflower varieties

\begin{tabular}{|c|c|c|c|c|c|c|c|c|c|c|c|c|}
\hline \multirow{3}{*}{$\begin{array}{c}\begin{array}{c}\text { Zaman } \\
\text { Uygulaması }\end{array} \\
\text { Haziran-12 }\end{array}$} & \multicolumn{6}{|c|}{ Tabla Çapı(cm) } & \multicolumn{6}{|c|}{1000 Tane Ağırığı(gr) } \\
\hline & \multicolumn{2}{|c|}{2010} & \multicolumn{2}{|c|}{2011} & \multicolumn{2}{|c|}{ Ortalama } & \multicolumn{2}{|c|}{2010} & \multicolumn{2}{|c|}{2011} & \multicolumn{2}{|c|}{ Ortalama } \\
\hline & 24.4 & $\mathrm{a}$ & 21.4 & $\mathrm{a}$ & 22.9 & $a$ & 58.8 & $\mathrm{a}$ & 59.1 & $a$ & 58.9 & $\mathrm{a}$ \\
\hline Haziran-22 & 22.9 & $a b$ & 21.1 & $a b$ & 22.0 & $a$ & 52.5 & $b$ & 58.5 & $a b$ & 55.5 & $\mathrm{~b}$ \\
\hline Haziran-02 & 20.5 & $b$ & 19.6 & bc & 20.0 & $\mathrm{~b}$ & 48.1 & c & 55.8 & $b$ & 51.9 & c \\
\hline Haziran-12 & 16.5 & $\mathrm{c}$ & 18.8 & $\mathrm{~cd}$ & 17.6 & c & 43.8 & $d$ & 52.1 & c & 48.0 & d \\
\hline Haziran-22 & 14.0 & $c$ & 17.1 & $d$ & 15.5 & $d$ & 36.5 & $\mathrm{e}$ & 50.1 & $c$ & 43.3 & $\mathrm{e}$ \\
\hline Ortalama & \multicolumn{2}{|c|}{19.6} & \multicolumn{2}{|c|}{19.6} & \multicolumn{2}{|c|}{19.6} & \multicolumn{2}{|c|}{47.9} & \multicolumn{2}{|c|}{55.1} & \multicolumn{2}{|c|}{51.5} \\
\hline C.V.(\%) & \multicolumn{2}{|c|}{14.87} & \multicolumn{2}{|c|}{7.26} & \multicolumn{2}{|c|}{11.27} & \multicolumn{2}{|c|}{4.41} & \multicolumn{2}{|c|}{4.32} & \multicolumn{2}{|c|}{4.18} \\
\hline $\operatorname{LSD}(0.05)$ & \multicolumn{2}{|c|}{3.57} & \multicolumn{2}{|c|}{1.74} & \multicolumn{2}{|c|}{1.83} & \multicolumn{2}{|c|}{2.59} & \multicolumn{2}{|c|}{2.92} & \multicolumn{2}{|c|}{1.79} \\
\hline
\end{tabular}

* Her bir sütundaki aynı harfi taşıyan ortalamalar arasındaki fark önemsizdir $(P<0.05)$

*. Differences between averages with same letter in a column are statistically not important $(P<0.05)$

düşük bin tane ağırlığı ise Temmuz-22 ekiminden (43.3 gr) elde edilmiştir (Çizelge 4). Ayçiçeğinde en önemli verim unsurlarından olan bin tane ağırlığı, genotipe ve yetiştirme şartlarına göre değişiklik göstermektedir (Illbaş ve ark. 1996). Genotipe ve yetiştirme koşullarına bağlı olarak değişim gösteren yağ oranı bakımından en yüksek değer Haziran-12 (\%40.37) ekiminden elde edilmiştir (Çizelge 5). Ayçiçeğinde tohumun kimyasal bileşimi değişik faktörlere bağlı olarak farklılıklar göstermektedir. Yetişme koşulları, sıcaklık, gübreleme, sulama ve çeşit özellikleri bu faktörlerin başında gelmektedir. Tohum oluşumu devresindeki yüksek sıcaklık, yağ oranını azaltıcı etki yapmaktadır (Gürbüz ve ark. 2003). Yağ oranı bakımından ayçiçeği çeşitlerinin yıllara, lokasyonlara ve yıl içerisinde birbirlerine göre farklııklar oluşturması, çeşitlerin genetik yapılarının ve yıllara ilişkin ekolojik değişkenlerin farklı olmasından kaynaklanmaktadır (Kıllı, 1995). $\mathrm{Bu}$ durum, ayçiçeğinde yağ oranının genotip yanında çevresel faktörler ve kültürel uygulamalardan etkilendiğini bildiren araştırma sonuçlarıyla da teyit edilmiştir (Özer ve ark. 2003).

Bitki yetiştiriciliğinde en önemli karakterlerden birisi tane verimidir. Bu çalışmada da farklı ekim zamanları arasında önemli tohum verimi farklılıkları bulunmuştur. İkinci ürün koşullarında bölgemizde en uygun ekim zamanının belirlenmesi için yapılan çalışmada, Haziran-12 ekim zamanı en yüksek tohum verimini (349.7 $\mathrm{kg} / \mathrm{da})$ verirken bunu Haziran-22 $(264.5 \mathrm{~kg} / \mathrm{da})$ ve Temmuz-02 $(237.3 \mathrm{~kg} / \mathrm{da})$ izlemiştir. En düşük verim ise Temmuz-22 ekim zamanından elde edilmiştir (Çizelge 5).

Ayçiçeğinde tane verimi çok sayıda öğe tarafından oluşturulmakta olup genetik yapının yanı sıra ekolojik, morfolojik, fizyolojik ve agronomik yönden pek çok faktör verime etki etmektedir (Bange et al. 1997). Bitkide belirtilen normal ekim zamanından uzaklaşıldıkça yapılacak olası ekimlerin tohum verimini de önemli ölçüde azalttığı (Vega ve ark. 2002, 
Çil et al. "A Study on Determination of the Best Sowing Date for Sunflower (Helianthus annuus L.) as Second Crop in Çukurova Conditions"

Çizelge 5. Denemeye alınan ayçiçeği çeşitlerinin incelenen özelliklere ait ortalama değerler Table 5. Averages of some traits of sunflower varieties

\begin{tabular}{ccccccccccccccccccc}
\hline \multirow{2}{*}{$\begin{array}{c}\text { Zaman } \\
\text { Uygulaması }\end{array}$} & \multicolumn{4}{c}{ Yağ Oranı(\%) } & \multicolumn{4}{c}{ Yağ Verimi(kg/da) } & \multicolumn{4}{c}{ Tane Verimi(kg/da) } \\
\hline Haziran-12 & 40.47 & a & 40.27 & a & 40.37 & a & 120.8 & a & 161.8 & a & 141.3 & a & 298.7 & a & 400.6 & a & 349.7 & a \\
Haziran-22 & 39.45 & a & 36.52 & b & 37.98 & b & 67.1 & b & 130.9 & b & 98.98 & b & 170.5 & b & 358.4 & b & 264.5 & b \\
Haziran-02 & 37.15 & ab & 35.65 & b & 36.40 & b & 53.0 & b & 118.8 & b & 85.89 & c & 141.3 & b & 333.3 & b & 237.3 & c \\
Haziran-12 & 35.35 & b & 32.32 & c & 33.83 & c & 34.9 & c & 97.2 & c & 66.07 & d & 97.9 & c & 300.4 & c & 199.1 & d \\
Haziran-22 & 28.32 & c & 31.75 & c & 29.96 & d & 24.2 & c & 81.6 & d & 52.36 & e & 84.1 & c & 257.5 & d & 169.7 & e \\
\hline Ortalama & 36.1 & 35.3 & 35.7 & 60 & 118.1 & 88.9 & 158.5 & 330.1 & 244.1 \\
\hline C.V.(\%) & 8.88 & 6.74 & 7.77 & 22.64 & 9.92 & 14.12 & 20.08 & 7.14 & 11.02 \\
LSD(0.05) & 3.84 & 2.92 & 2.3 & 16.26 & 14.35 & 10.41 & 38.95 & 28.81 & 22.27 \\
\hline
\end{tabular}

${ }^{*}$ Her bir sütundaki aynı harfi taşıyan ortalamalar arasındaki fark önemsizdir $(P<0.05)$

* Differences between averages with same letter in a column are statistically not important $(P<0.05)$

D'Andria ve ark. 1995); erken ekildiğinde ise verim düzeyinin \%25-35 artma gösterdiği saptanmıştır (Alkan 1973). Çalışmada yağ verimi bakımından ekim zamanları arasında görülen farklılıklar istatistikî açıdan önemli bulunmuştur. Ham yağ verimi en yüksek $141.3 \mathrm{~kg} / \mathrm{da}$ ile Haziran-12 ekiminden elde edilirken, en düşük ham yağ ortalaması ise $52.36 \mathrm{~kg} / \mathrm{da}$ ile Temmuz22 ekiminde tespit edilmiştir. Denemede 2010 yılı verileri incelendiğinde, önemli veri kayıplarının olduğu görülmektedir. Bunun nedeni bölgemizde geç ekimi yepılan yağlı tohumlu bitkilerde beyaz sinek ve akabinde pas hastalıkları yoğun bir şekilde etkilemektedir. Bu durum, genellikle geç ekim yapılan ayçiçeği tarlalarında çiçeklenmeden sonra ortaya çıkan ve etmeni Puccinia helianthi Schw. olan pas hastalığının ayçiçeği üretimini önmeli derecede etkilediği Süzer (1991) tarafından da bildirilmiştir.

Tane verimi ve yağ oranının bir bileşkesi olan yağ verimi, çeşit özelliği olarak ortaya çıktığı gibi, tohum verimi ve yağ oranını etkileyen tüm yetiştirme koşulları ve ekolojik faktörlerin de etkisi altındadır (Ashley 2001). Bütün yağ bitkilerinde ekonomik açıdan en önemli verim kriteri yağ verimidir. Nitekim İlisulu (1970), araştırmalarda çeşitlerin yağ verimlerinin hesaplanması gerektiğini bildirmektedir. Ortam sıcaklığı ve toprak nemi tohumdaki yağ miktarını olumlu yönde etkilemekte (Yücel ve ark. 1977); ancak geç ekimde yağ oranı azaldığı gibi (Ashley 2001; Leto 1998) yağ kalitesi de (özellikle de oleik ve linoleik asit oranı) değiştirmektedir (Blamey 1997). Erken ve geç, ekilen bitkilerdeki toprak üstü aksam farklıııkları, ekim zamanının verime olan etkisinin en belirgin göstergesidir (İlisulu 1973; Vega et al. 2002).

\section{Sonuç}

Çukurova Bölgesinde II. Ürün koşullarında yetiştirilecek yağlık ayçiçeği için en uygun ekim zamanı 12 Haziran olarak belirlenmiştir. Ancak ekim zamanı erkene çekildikçe verimin arttığı belirlenmiştir. Geç ekimlerde yağ oranı ve tohum sayısı/tabla oranında azalma olmakta ve tohum veriminin düşmesine yol açmaktadır. Bu durum aynı zamanda tohum verimine ekim zamanının dolaylı etkisine de sebep olmaktadır (Beard and Geng 1982).

\section{Kaynaklar}

Aiello G.M., Cubeddu M., Mura C., Soddu A., 1999. Different water regimes for sunflowers in Sardinia. Inform. Agrario, 55: 31-33

Alkan B., 1973. Ayçiçeği tarımı ve gübrelenmesi. Toprak ve Gübre Araşt. Enst. Md.lüğü Yayın No: $15,4-5$

Anonim, 2015. Türkiye İstatistik Kurumu Web sayfası.www.tuik.gov.tr/, (Erişim tarihi: 25.06.2015)

Ashley R.O., Eriksmoen E.D., Whitney M.B., 2001. Sunflower date of planting study in Western North Dakota. In 2001 Annual Report, Dickinson Research Extension Centres, Dickinson, ND, 187-198

Beard H.B., Geng S., 1982, interrelationships of morphological and economic characters of sunflower. Crop Sci., 22: 817-822

Biçer Y., 1987, Çukurova'da Buğdaydan Sonra İkinci Ürün Mısır Tarımında Toprak İşleme Tekniği. Köy Hizmetleri Genel Müdürlüğü Tarsus Araştırma Enstitüsü, Gn. Yayın No: 138, Rapor Serisi No: 79, Tarsus

Blamey F.P.C., Zollinger R.K., Schneiter A.A., 1997, Sunflower Production and Culture, (Editör: 
Çil ve ark. "Çukurova Koşullarında II. Üründe Yetiştirilecek Yağlık Ayçiçeğinde (Helianthus annuus L.) En Uygun Ekim Zamanının Belirlenmesi Üzerine Bir Araştırma"

Schneiter AA). In Sunflower Technology and Production Agron Mongr. 35. ASA, CSSA, and SSSA, Madison, WI, 595-670

D’Andria R., Chiarandá F.Q., Magliulo V., Mori M., 1995. Yield and soil water uptake of sunflower sown in spring and summer. Argon. J., 87: 1122-1128

Dinç U., 1990. Çukurova Bölgesi Toprakları. Ç. Üniv. Ziraat Fak. No: 25, Adana

İlisulu K., 1973. Yağ Bitkileri ve Islahı. Çağlayan Basımevi (İstanbul), 1. Baskı, 140-158

Kolsarıcı Ö., Gür A., Başalma D., Kaya M.D. ve İşler N., 2006. Yağlı tohumlu bitkiler üretimi, Tarım ve Mühendislik, Sayı: 78-79

Kolsarıcı Ö., Geçit H.H., Elçi Ş., 1987. Tarla Bitkileri. Ankara Üniv. Ziraat Fak. Yayın No: 1008, 103-118

Leto C., 1998. Sunflowers in south central Italy. Informatore Agrario, 54: 47-56

Madran N., 1991. Yeni Tarım Klavuzu. Hacettepe Taş Kitapçılık Ltd. Ankara
Taşkaya Top B., Uçum İ., 2012. Türkiye'de bitkisel yağ açığı. Tarımsal Ekonomi ve Politika Geliştirme Enstitüsü Yayını.Temmuz 2012 / ISSN: 1303-8346 / Sayı:14/Nüsha:2

Süzer S., 1991. Ayçiçeği Tarımında Ekilecek Hibrit Tohumluk Seçimi. Hasad, 76: 14-15

Süzer S., 2002. Ayçiçeği Tarımı. Cinetarım, 5: 3841

Tansı V., 1987. Çukurova Bölgesinde Mısır ve Soyanın İkinci Ürün olarak Değişik Ekim Sistemlerinde Birlikte Yetiştirilmesinin Tane ve Hasıl Yem Verimine Etkisi Üzerine Araştırmalar (Doktora Tezi). 1987

Vega A.J., Hall A.J., 2002. Effects of Planting Date, Genotype and Their Interactions on Sunflower Yield: I. Determinants of OilCorrected Grain Yield. Crop Sci., 42: 1191-1201

Yücel E., Yazıcı Y., Özsaraç M., Ünal E., Yücer M., Eğilmez Ö., Çuhadar İ., Şanlı Ö., 1977. Ayçiçeği Projesi El Kitabı. Tarım ve Köyişleri Bakanlığı, Yayın No: 170, 14-35 